\title{
A vasculonecrotic Type 2 Lepra Reaction Mimicking Lucio Phenomenon
}

\author{
Shreya Pradipbhai Somani, Hita H. Hemant, Mehta Milan, Dilipkumar Jhavar, Bhavesh N Astik, Rahul \\ Lakhotia \\ Department of Dermatology, Government Medical College, Bhavnagar, Gujarat, India
}

\begin{abstract}
Multibacillary, lepromatous or borderline leprosy patients may present two types Vasculonecrotic reactions: Erythema Nodosum Leprosum (ENL) with vasculitis and Lucio Phenomenon. ENL is Type 2 Lepra Reaction while Lucio Phenomenon commonly seen in nonnodular diffuse leprosy patients, mainly reported from Mexico. Here we reported a case of 20 year old male, RFT (Relief From Treatment) leprosy patient presented with fever, malaise, joint pain, edema over hands and feet and red tender elevated nodules. Interestingly, within 3 days of admission he developed multiple vesicular erythema multiforme like eruption on chest, back and upper extremity, which broken down to form necrotic ulcer in following 4 days. Biopsy showed leucocytoclastic vasculitis and fibrin deposition in vessel walls. Furthermore, USG of both ulnar nerves showed thickening. These clinical and histopathological features helped us to arrive at the diagnosis of the ENL with vasculonecrotic phenomenon. J Microbiol Infect Dis 2019; 9(3):133-136.
\end{abstract}

Keywords: Lepra reaction, vasculonecrotic phenomenon, ENL, Lucio Phenomenon

\section{INTRODUCTION}

Leprosy is a disease of slow development that presents a wide spectrum of clinical, histopathological and immunological characteristics [1]. Lepra reactions (type 1 and 2) are immunological phenomenon that occurs before, during or after completion of MDT [2]. But the vasculonecrotic (VN) reactions in leprosy could be present either as Erythema Nodosum Leprosum (Type 2 Lepra Reaction) or as Lucio Phenomenon [3]. Among these Type 2 Lepra Reaction (T2R) popularly known as Erythema Nodosum Leprosum (ENL) causes inflammation of skin, nerves and other organs by immune complex deposition. It has been noted that over $50 \%$ of lepromatous leprosy patients and $25 \%$ of borderline leprosy patients experience ENL [4]. Besides red tender nodules, unusual presentation of ENL lesions like vesiculobullous, ulcerative, hemorrhagic, erythema multiforme have also been reported [3]. Among these, vasculonecrotic ENL poses diagnostic difficulty as it mimics other cutaneous necrotizing disorders. Lucio Phenomenon is a rare reaction pattern in Lucio leprosy, while endemic in
Mexico [5]. But in recent past it has also been reported from India. In inadequately treated patients it presents as erythmatous spots that progress into superficial angular ulcers with burning sensation [6]. So patients of type 2 reaction with extensive eschars often look like Lucio Phenomenon.

We hereby, report a RFT (relief from treatment) case of Type 2 Lepra Reaction with vasculonecrotic phenomenon.

\section{CASE}

A 20-year-old, RFT leprosy patient, presented to outpatient department of Sir T Hospital, Bhavnagar with complains of fever, malaise, joint pain, edema over hands, feet and face and multiple elevated red tender nodules on face, chest, back and upper extremity for 7 days. For which he was admitted and treated with systemic steroid, cap thalidomide, injectable antibiotics and supportive treatment. After 3 days of admission, multiple discrete to confluent annular erythematous vesicular eruptions mimicking Erythema Multiforme (EM) developed on pre-existing nodules. So we changed the

Correspondence: Dr. Hita H. Mehta, Department of Dermatology, Government Medical College, Bhavnagar, Gujarat, India E-mail: hitamehta88@gmail.com

Received: 29 December 2018 Accepted: 25 June 2019

Copyright (C) JMID / Journal of Microbiology and Infectious Diseases 2019, All rights reserved 
antibiotics with thought of drug induced EM. But lesions went on increasing and bursted open into raw areas. This leads to development of necrotic ulcers having thick brown crusting.

In past history, patient had completed Multi Bacillary Multi Drug Therapy (MBMDT) for lepromatous leprosy in May 2017. In past 1.5 year, he developed remission and relapses with bouts of ENL reaction (having fever with tender nodules) for about 7-8 times and managed by systemic steroids and cap thalidomide. He also had history of recurrent epistaxis, headache, cough and cold. He had no history of contact with leprosy case, hair loss or recurrent unnoticed trauma. There was no history suggestive of neuritis, orchitis, iritis, glomerulonephritis, claw hand or foot drop in past. Patient had no past history of jaundice, tuberculosis or blood transfusion.

On cutaneous examination he had multiple, well demarcated, irregular shaped ulcers with necrosis and crusting having hypopigmented margin ranging from $3 \times 1.5$ to $6 \times 4 \mathrm{~cm}$ present on face, upper extremity, trunk, back and lower extremity. The involved body surface area was approximately $28 \%$ (Figure 1 ). Along with that, patient was having puffiness of face and depressed nose. Besides this, both side ulnar and popliteal nerves were symmetrically thickened, palpable and non-tender. Bilateral glove and stocking anesthesia was present. Patient was able to perform routine activities like dressing, buttoning shirt, holding things. Examination of cranial nerve was normal.

His hemogram revealed hemoglobin of 11.1 $\mathrm{gm} / \mathrm{dl}$, total leucocytes were $17,000 / \mathrm{dl}$, differential count showed neutrophilic leukocytosis. Erythrocyte sedimentation rate was $86 \mathrm{~mm} / \mathrm{hr}$. Liver and renal function tests and serum electrolytes were within normal range. HBsAg, HCV and HIV 1 \& 2 were non-reactive. Slit skin smear from ear lobule showed no AFB bacilli. His bacteriological culture from left upper arm isolated staphylococcus aureus. But no organism isolated from urine and blood culture. USG local part of inguinal region revealed, soft tissue and muscular edema with multiple enlarged $\mathrm{B} / \mathrm{L}$ inguinal lymph nodes. Along with that USG of both ulnar nerves showed hypoechoic area with increased circumference and fusiform thickening (Figure 2).

Histopathological sections showed leucocytoclastic vasculitis involving various small vessels of superficial and deep plexuses. Affected vessels showed abundant deposition of fibrin in the wall. Involved vessels were surrounded by extravasated RBC, neutrophils, and nuclear dust. Overlying epidermis was atrophied (Figure 2).

Patient was treated with Prednisolone $40 \mathrm{mg}$ for 7 days which gradually tapered by $10 \mathrm{mg}$ weekly after clinical improvement and thereafter by $5 \mathrm{mg}$ weekly over 1 month and Cap Thalidomide $100 \mathrm{mg}$ TDS for 7 days followed by maintenance dose of $100 \mathrm{mg}$ for 2 months along with that local part dressing. He was also given Piperacillin/Tazobactam $4.5 \mathrm{gm}$ iv 12 hourly for 7 days and thereafter Inj. Meropenam1gm iv 8 hourly for 10 days. Patient showed improvement in lesions within 2 weeks.

Table 1. The differentiations the ENL with vasculitis from Lucio Phenomenon.

\begin{tabular}{|c|c|c|}
\hline Case & Present Case & Lucio Phenomenon \\
\hline Diagnosis & RFT leprosy patient & Untreated diffuse leprosy ${ }^{(6)}$ \\
\hline Lesion & Extensive and deep necrotic lesions & Superficial angulated ulcers ${ }^{\lfloor 4,5\rfloor}$ \\
\hline Pain type & Ischaemic pain & Burning sensation ${ }^{[\mathrm{b}\rfloor}$ \\
\hline Fever & Fever present & Usually afebrile ${ }^{[b]}$ \\
\hline Nerve affect & Tender nerves and neuritis & Does not affect nerves ${ }^{\lfloor b\rfloor}$ \\
\hline Symptoms & Arthralgia, lymphadenitis & No constitutional symptoms or visceral damage $e^{\lfloor b]}$ \\
\hline Histopathology & $\begin{array}{c}\text { Superficial and deep luecocytoclastic vasculitis } \\
\text { with epidermal necrosis. There is Perivascular } \\
\text { nuertophilic infiltrates and dense fibrin } \\
\text { deposition in vessel wall. }\end{array}$ & $\begin{array}{l}\text { Superficial leukocytoclastic vasculitis with } \\
\text { epidermal necrosis. There are numerous } \\
\text { macrophages containing AFB and endothelial cell } \\
\text { prolifelation of small vessel walls. }\end{array}$ \\
\hline
\end{tabular}



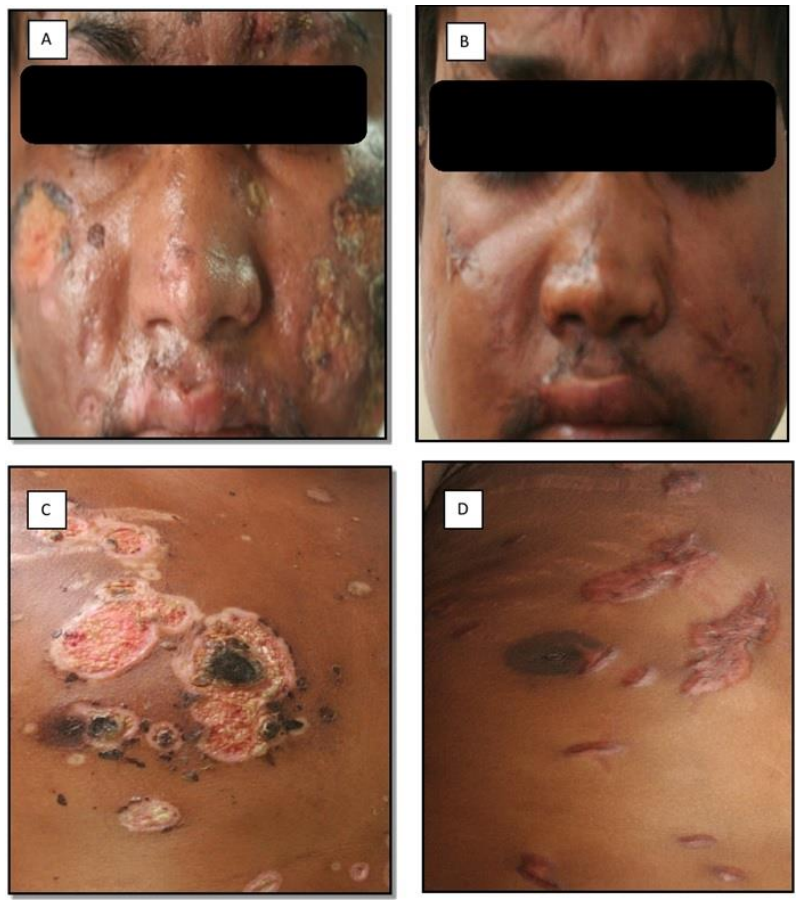

Figure 1. Image A and B showing multiple well defined, irregular shaped ulcers with necrosis, crusting and hypopigmented margin on face and chest respectively. Image $C$ and D showing multiple fibrotic scars on face and chest, respectively.
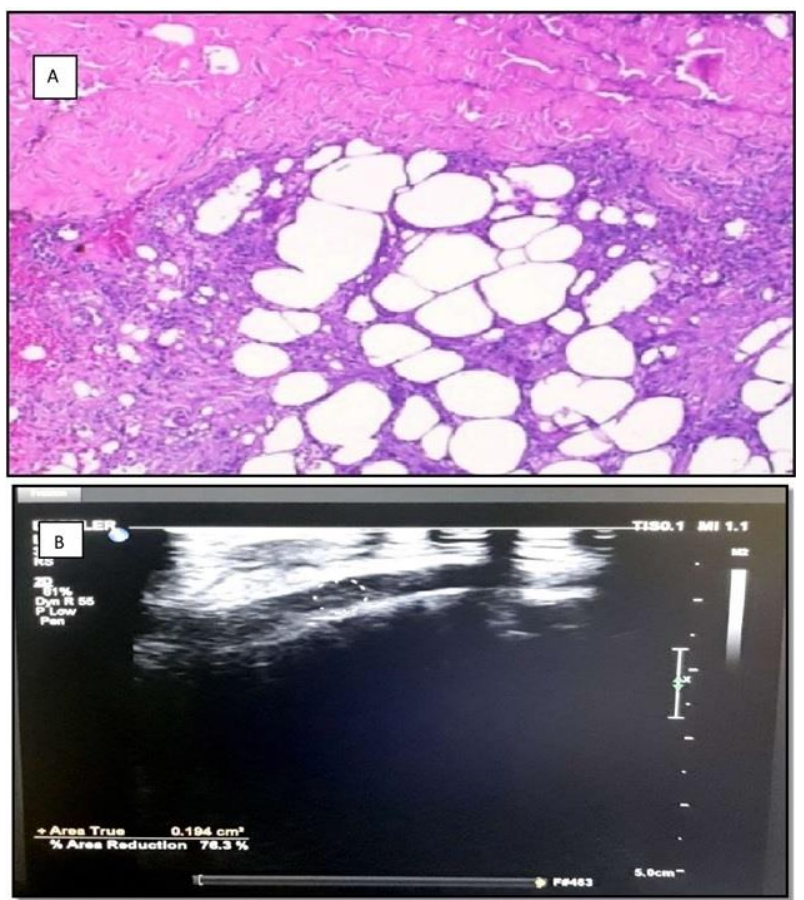

Figure 2. Investigation done in the case: Image $A$ is histopathology, Image B is Histopathology is USG of ulnar nerves.

\section{DISCUSSION}

ENL is an immune complex mediated hypersensitivity reaction, which commonly manifests as sudden appearance of crops of erythematous, edematous and tender nodules and plaques associated with fever and joint pain[7]. Besides the classical lesions of Type 2 Lepra Reaction, rare presentation of vesiculobullous, pustular, necrotic, erythemamultiforme like lesions were also reported [4]. The sequalae of above mentioned rare presentation is erythema nodosum necroticans which manifest as deep tender ulcers with central necrosis having sloping edge and thick brown crusting.

Fogangolo et al reported two cases of vasculonecrotic reaction in lepromatous leprosy patients: one of necrotic ENL and other of Lucio Phenomenon in which he mentioned that vasculonecrotic (VN) ENL usually occurs in multibacillary $\mathrm{LL}$ and $\mathrm{BL}$ cases after starting MBMDT $[4,6]$ in contrast to Lucio Phenomenon which occurs predominantly in untreated or inadequately treated patient $[4,6]$. Clinically he noticed deep ulcers associated with constitutional symptoms, visceral involvement and neuritis in patient of ENL $[4,6]$ while lesions in LP are painful, tender, red patches which turn purpuric and later ulcerate centrally to form necrotic ulcer with angulated margin $[4,6]$. Similarly, our patient of ENL had deep necrotic ulcers with constitutional symptoms and neuritis but he had completed anti leprosy treatment for 12 months and this is an interesting finding in our patient. The detailed difference between the two has been depicted in Table 1. The former heals with fibrotic scars while later with superficial atrophic scars. Similar fibrotic scars were also observed in our patient (Figure 1).

Only small number of reported cases of vasculonecrotic ENL in world literature suggests that it is fairly uncommon [8]. Vashisht et al described a rare presentation of bullous ENL on trunk in multibacillary leprosy case on MBMDT [9]. Swain et al reported a case of necrotic ENL lesions in oral cavity along with involvement of usual sites [9]. In contrary to all reported cases of necrotic ENL who were on MBMDT, our patient had completed a full course of MDT.

By implying above mentioned observations of various studies [4-9], presence of deep necrotic 
ulcers, constitutional symptoms, tender nerves, classical histopathological findings and marked response to thalidomide favors the diagnosis of ENL and rule out the possibility of LP.

Few ulcerative lesions were mimicking pyoderma gangrenosum but extensivity of lesions and presence of other leprosy findings differentiate from it.

This report highlights the rare presentation of erythema nodosum leprosum with vasculonecrotic phenomenon in immunocompetent and RFT leprosy patient.

\section{ACKNOWLEDGMENTS}

Declaration of Conflicting Interests: The authors declare that they have no conflict of interest.

Funding: This project received no specific grant from any funding agency in the public, commercial, or not-for-profit sectors.

\section{REFERENCES}

1. Belgaumkumar VA, Chavan RB, Salunle AS, Chirame SS. De-novo Ulceration - Rare Lazarine leprosy- like presentation of Borderline Lepromatous Hansen's Disease. Indian J Lepr 2018; 90:69-73

2. Kahawita IP; Walker SL, Lockwood DNJ. Leprosy type 1 reactions and erythema nodosum Leprosum. An Bras Dermatol 2008; 83 (1):75-82.

3. Ranugha $P$, Chandrashekhar L, Kumari R, Thappa DM, Badhe B. Is It Lucio Phenomenon or Necrotic Nodosum Leprosum? Indian J Dermatol. 2013; 58(2):160.

4. Voorend CG, Post EB. A Systematic Review on the Epidemiological Data of Erythema Nodosum Leprosum, a Type 2 Leprosy Reaction. PLoS Negl Trop Dis 2013 (10): e2440.

5. Bharti AH, Patel P. A Case of Hansen's Disease Presenting with Lucio Phenomenon from Gujarat, India. Indian J Lepr 2017, 89: 217-224.

6. Fogangolo L; de Souza EM; Cintra ML, Vehlo PENF. Vasculonecrotic reactions in leprosy. Braz J Infect Dis. 2007; 11(3):378-382. 